Pauling, P. (1969). The Nature of the Chemical Bond, 2nd ed. pp. 164 179, 346. Ithaca: Cornell Univ. Press.

Probts, T., StiegelmanN, O., Reide, J. \& Schmidbaur, H. (1991). Chem. Ber. 124, 1089-1093.

Acta Cryst. (1995). B51, 300-307
Reddy, J. P., Ravichandran, V., Chacko, K., Weber, E. \& SaEnger, W. (1989). Acta Cryst. C45, 1871-1874.

VRANKa, R. G. \& AMma, E. L. (1966). Inorg. Chem. 5, 1020-1025.

WiEst, R. \& WeIss, R. (1973). J. Chem. Soc. Chem. Commun. pp. 678679.

\title{
More Space-Group Changes
}

\author{
BY RICHARD E. MARSH \\ The Beckman Institute, ${ }^{*}$ California Institute of Technology, Pasadena, CA 91125, USA \\ AND IVAN BERNAL \\ Department of Chemistry, University of Houston, Houston, TX 77204-5641, USA
}

(Received 9 June 1994; accepted 18 October 1994)

\begin{abstract}
Revisions are made to the space groups in ten published $\mathrm{X}$-ray diffraction studies. In five cases the revisions entail increases in the Laue symmetry and, except for repositioning a nitrate group in one compound, there are no important changes in the interatomic distances and angles. In four other cases, centers of symmetry have been added; in one of these cases further refinement has led to appreciable changes in the bond lengths and angles, while in the other three cases the original intensity data were not available and further refinement could not be carried out. In the tenth case, both the Laue symmetry has been increased and a center of symmetry has been added, and the structure further refined.
\end{abstract}

\section{Introduction}

We have come across a number of examples - some recent, some older - of crystal-structure determinations in which the chosen space group was of unnecessarily low symmetry. As has been our custom (Marsh \& Herbstein, 1988), we group the corrections to these space groups into two categories: (1) Change in Laue group; in such cases, the original coordinates should conform to the higher symmetry within their e.s.d.'s, and no significant changes in bond lengths or angles should result. (2) Addition of a center of symmetry within the same Laue group; in these cases, much larger coordinate shifts are usually involved, and where possible we have carried out additional refinements in the highersymmetry centrosymmetric space group. One example belongs to both categories.

In correcting these structures, we find three especially interesting examples. In one case, the original structure

${ }^{*}$ Contribute No. 8957. was seriously in error, the $\mathrm{NO}_{3}^{-}$counterion having been misplaced due, apparently, to unfortunate misprints in the published coordinates. In a second case, large errors in the measured cell dimensions - several times larger than the indicated precisions - presumably led the authors to assume a triclinic rather than a monoclinic unit cell, whereas the structure itself obeys monoclinic symmetry well within the e.s.d.'s of the coordinates. In a third case the proper rhombohedral unit cell was undetected, perhaps because of its extreme obliquity (the angle $\alpha$ is only $11.24^{\circ}$ ).

\section{Category 1: change in Laue group}

$\mathrm{PbAl}_{2} \mathrm{O}_{4}$ and $\mathrm{PbGa}_{2} \mathrm{O}_{4}$

The structures of these two isomorphous compounds (Plötz \& Müller-Buschbaum, 1982) were described as triclinic, space group $P 1, Z=2$. $\left(\mathrm{PbAl}_{2} \mathrm{O}_{4}: a=5.268\right.$, $b=8.458, \quad c=5.070 \AA, \quad \alpha=90.0, \quad \beta=118.78$, $\gamma=90.0^{\circ} ; \quad \mathrm{PbGa}_{2} \mathrm{O}_{4}: \quad a=5.387, \quad b=8.575$, $c=5.220 \AA, \quad \alpha=90.0, \quad \beta=118.99, \quad \gamma=90.0^{\circ}$; no e.s.d.'s reported.) The authors noted that the cell dimensions for both compounds correspond to centered orthorhombic lattices, but that they were unable to derive a satisfactory structure either in an orthorhombic space group or in the monoclinic space group $P 2_{1}$. In fact, the coordinates for both compounds agree well with space group Ama2, No. $40\left(a^{\prime}=b, b^{\prime}=2 a+c, c^{\prime}=-c\right)$. After suitable transformations $\left(x^{\prime}=y, \quad y^{\prime}=\frac{1}{2} x\right.$, $\left.z^{\prime}=\frac{1}{2} x-z\right)$ and averaging, the coordinates in Table 1 result. The shifts necessary to achieve the symmetry of Ama2, included in Table 1, seem satisfactorily small, but no e.s.d.'s are reported so we cannot make a formal comparison. Interatomic distances are, of course, effectively unchanged. 
Table 1. $\mathrm{PbAl}_{2} \mathrm{O}_{4}$ and $\mathrm{PbGa}_{2} \mathrm{O}_{4}$ : coordinates, space group Ama2

Numbers in square brackets are average shifts to the original $P 1$ coordinates necessary to achieve the symmetry of $A m a 2$.

$\mathrm{PbAl}_{2} \mathrm{O}_{4}(a=8.458, b=9.234, c=5.070 \AA)$

$\begin{array}{llccc} & \text { Site } & x & y & z \\ \mathrm{~Pb} & 4(b) & 0.2500[0] & 0.0299[0] & 0.0003[0] \\ \mathrm{Al} & 8(c) & 0.0541[4] & 0.6717[6] & 0.0327[3] \\ \mathrm{O}(1) & 8(c) & 0.0564[7] & 0.1908[4] & 0.1877[2] \\ \mathrm{O}(2) & 4(a) & 0.0000[6] & 0.5000[4] & 0.1412[1] \\ \mathrm{O}(3) & 4(b) & 0.2500[4] & 0.6849[4] & 0.1527[5]\end{array}$

$\mathrm{PbGa}_{2} \mathrm{O}_{4}(a=8.575, b=9.424, c=5.220 \AA)$

$\begin{array}{lllll}\mathrm{Pb} & 4(b) & 0.2500[0] & 0.0282[0] & -0.0021[1] \\ \mathrm{Ga} & 8(c) & 0.0524[6] & 0.6726[2] & -0.0403[1] \\ \mathrm{O}(1) & 8(c) & 0.0595[12]^{*} & 0.1826[9] & -0.1864[13] \\ \mathrm{O}(2) & 4(a) & 0.0000[22] & 0.5000[8] & -0.1743[6] \\ \mathrm{O}(3) & 4(b) & 0.2500[14] & 0.6906[10] & -0.1785[5]\end{array}$

* The original $y$ coordinate (space group $P 1$ ) of $\mathrm{O}_{V}$ was obviously misprinted as 0.8408 ; we assume the correct value to be 0.9408 , which leads to the reported bond lengths.

Table 2. $\left[\mathrm{NEt}_{4}\right]_{4}\left[\mathrm{Ni}_{6}\left(\eta^{2}-\mu_{6}-\mathrm{In}_{2} \mathrm{Br}_{5}\right)_{2}(\mathrm{CO})_{10}\right] \cdot \mathrm{Me}_{2} \mathrm{CO}$ : coordinates, space group $C 2 / c \quad(a=22.869$, $b=13.198, c=26.775 \AA, \beta=107.96^{\circ}$ )

Atom numbering is from Demartin, Iapalucci \& Longoni (1993). Numbers in square brackets are shifts necessary to achieve the symmetry of $C 2 / c$.

\begin{tabular}{|c|c|c|c|}
\hline & $x$ & $y$ & $z$ \\
\hline $\operatorname{In}(1)$ & $0.10203[2]$ & $0.65196[2]$ & $0.57764[7]$ \\
\hline $\operatorname{In}(2)$ & $0.11678[2]$ & $0.38402[2]$ & $0.58260[2]$ \\
\hline $\operatorname{Br}(1)$ & $0.17084[4]$ & $0.77971[1]$ & $0.54992[2]$ \\
\hline $\operatorname{Br}(2)$ & $0.19987[4]$ & $0.53021[12]$ & $0.64000[8]$ \\
\hline $\operatorname{Br}(3)$ & $0.08930[3]$ & $0.75828[15]$ & $0.65516[2]$ \\
\hline $\mathrm{Br}(4)$ & $0.20283[4]$ & $0.28534[7]$ & $0.56080[6]$ \\
\hline $\operatorname{Br}(5)$ & $0.10862[0]$ & $0.27350[18]$ & $0.66024[10]$ \\
\hline $\mathrm{Ni}(1)$ & $0.07864[7]$ & $0.50983[16]$ & $0.50124[1]$ \\
\hline $\mathrm{Ni}(2)$ & $-0.00680[5]$ & $0.63545[0]$ & $0.49636[6]$ \\
\hline $\mathrm{Ni}(3)$ & $0.01930[10]$ & $0.50656[6]$ & $0.57081[11]$ \\
\hline$C T(1)$ & $0.0403[14]$ & $0.6144[3]$ & $0.4446[12]$ \\
\hline $\mathrm{CT}(2)$ & 0.0509 [9] & $0.3886[4]$ & $0.4513[3]$ \\
\hline$O T(1)$ & $0.0589[4]$ & $0.6648[5]$ & $0.4182[1]$ \\
\hline $\mathrm{OT}(2)$ & $0.0750[4]$ & $0.3383[0]$ & $0.4277[0]$ \\
\hline$C(1)$ & $0.1550[11]$ & $0.5226[16]$ & $0.4966[7]$ \\
\hline $\mathrm{C}(2)$ & $-0.0102[4]$ & $0.7694[12]$ & $0.4910[7]$ \\
\hline $\mathrm{C}(3)$ & $0.0321[0]$ & $0.5108[2]$ & $0.6392[1]$ \\
\hline$O(1)$ & $0.2012[2]$ & $0.5346[4]$ & $0.4908[2]$ \\
\hline$O(2)$ & $-0.0125[0]$ & $0.8553[2]$ & $0.4871[3]$ \\
\hline$O(3)$ & $0.0354[6]$ & $0.5110[6]$ & $0.6827[1]$ \\
\hline$N(1)$ & 0.2251 [5] & $0.5205[6]$ & $0.8104[4]$ \\
\hline$N(3)$ & $0.0984[4]$ & $0.0073[2]$ & $0.4007[4]$ \\
\hline$C(111)$ & $0.2952[8]$ & $0.5248[8]$ & $0.8245[6]$ \\
\hline$C(112)$ & $0.3196[4]$ & $0.5200[11]$ & $0.7777[4]$ \\
\hline$C(121)$ & $0.2012[4]$ & $0.4236[2]$ & $0.7794[8]$ \\
\hline$C(122)$ & $0.2248[3]$ & $0.3253[8]$ & 0.8087 [6] \\
\hline$C(131)$ & $0.2106[4]$ & $0.5246[4]$ & $0.8606[4]$ \\
\hline$C(132)$ & 0.1435 [7] & $0.5183[5]$ & $0.8556[0]$ \\
\hline$C(141)$ & $0.1960[12]$ & $0.6083[5]$ & $0.7744[8]$ \\
\hline$C(142)$ & $0.2122[5]$ & $0.7125[8]$ & $0.7978[4]$ \\
\hline$C(311)$ & $0.0986[1]$ & 0.0344 [9] & $0.3467[13]$ \\
\hline$C(312)$ & $0.0800[5]$ & $0.1375[0]$ & $0.3260[10]$ \\
\hline$C(321)$ & $0.1090[13]$ & $-0.1028[5]$ & $0.4094[0]$ \\
\hline$C(322)$ & $0.1694[3]$ & $-0.1448[1]$ & $0.4088[4]$ \\
\hline$C(331)$ & $0.0368[10]$ & $0.0370[8]$ & $0.4071[5]$ \\
\hline C(332) & $-0.0184[0]$ & $-0.0145[11]$ & $0.3712[0]$ \\
\hline$C(341)$ & $0.1474[0]$ & $0.0695[1]$ & $0.4398[0]$ \\
\hline$C(342)$ & $0.1574[14]$ & $0.0454[4]$ & $0.4959[12]$ \\
\hline$O(900)$ & $0.0000[2]$ & $0.8688[-]$ & $0.2500[5]$ \\
\hline $\mathrm{C}(900)$ & $0.0000[12]$ & $0.7762[-]$ & $0.2500[4]$ \\
\hline$C(901)$ & $0.0532[13]$ & $0.7222[6]$ & $0.2853[6]$ \\
\hline
\end{tabular}

$\left[\mathrm{NEt}_{4}\right]_{4}\left[\mathrm{Ni}_{6}\left(\eta^{2}-\mu_{6}-\mathrm{In}_{2} \mathrm{Br}_{5}\right)_{2}(\mathrm{CO})_{10}\right] \cdot \mathrm{Me}_{2} \mathrm{CO}$

The structure of this cluster compound, $\mathrm{C}_{45} \mathrm{H}_{86} \mathrm{~N}_{4} \mathrm{O}_{11} \mathrm{Br}_{10} \mathrm{In}_{4} \mathrm{Ni}_{6}$, was described (Demartin, Iapalucci \& Longoni, 1993) as triclinic, space group $P \overline{1}$, with $a=13.230(11), \quad b=13.198(7), \quad c=26.519(6) \AA$, $\alpha=75.44(3), \beta=88.69(4), \gamma=59.80(5)^{\circ}, Z=2$; it should be described as monoclinic, space group $C 2 / c$. The vectors $(2 \overline{1} 0),(0 \overline{1} 0)$ and $(\overline{1} 1 \overline{1})$ describe a cell with $a=22.869, \quad b=13.198, \quad c=26.775 \AA, \quad \alpha=89.74$, $\beta=107.96, \quad \gamma=90.28^{\circ}, \quad Z=4$; the corresponding coordinate transformations are $x^{\prime}=\frac{1}{2}(x-z)$, $y^{\prime}=-y-\frac{1}{2}(x+z), z^{\prime}=-z$. After averaging over pairs of equivalent atoms, the coordinates in Table 2 result.

In this case, the deviations of the monoclinic cell angles $\alpha$ and $\gamma$ from the ideal value of $90^{\circ}$ are quite large and appear to be statistically significant. However, coordinates of equivalent atoms conform to the higher symmetry well with their e.s.d.'s - the deviations are never as much as $0.035 \AA$ for a light atom $(\mathrm{C}, \mathrm{N}, \mathrm{O})$ or as much as $0.003 \AA$ for a heavy atom (Ni, Br, In). Thus, the structure indeed has the symmetry $C 2 / c$, and the apparent angle deviations are surely spurious. It seems clear that this is one of numerous examples where the e.s.d.'s reported for cell dimensions are estimates only of the precision of the measurements, not of the accuracy. Systematic errors due to mis-centering of the crystal, mis-alignment of the diffractometer, or a poor selection of calibrating reflections can result in cell dimensions that are in error by amounts far larger than the nominal e.s.d.'s, particularly in the case of highly absorbing crystals (such as the present example) where much of the diffraction occurs at the surface of the crystal rather than at the center of the diffractometer, leading to systematic errors in the measured $2 \theta$ values.

\section{$\mathrm{K}_{2.5}\left(\mathrm{H}_{5.5} \mathrm{PtW}_{6} \mathrm{O}_{24}\right) \cdot 2 \mathrm{H}_{2} \mathrm{O}$}

The structure of this compound (Lee \& Sasaki, 1987) was described as triclinic $[a=11.443(2)$, $b=13.674(1), \quad c=11.427(2) \AA, \quad \alpha=101.36(2)$, $\beta=119.94(2), \gamma=84.35(2)^{\circ}$, space group $\left.P \overline{1}, Z=2\right]$. The lattice vectors (001), (201) and (010) define a $C$-centered monoclinic cell $\left(a^{\prime}=11.427, b^{\prime}=19.832\right.$, $c^{\prime}=13.674 \AA, \alpha^{\prime}=89.99, \quad \beta^{\prime}=101.36, \quad \gamma^{\prime}=89.99^{\circ}$, $Z=4)$; the corresponding coordinate transformations $x^{\prime}=-\frac{1}{2} x+z, y^{\prime}=\frac{1}{2} x, z^{\prime}=y$ result in values that are with two exceptions - consistent with space group $C 2 / m$. The two exceptions probably represent misprints in the $P \overline{1}$ coordinates (Lee \& Sasaki, 1987; Table 1): the $z$ coordinate of $\mathrm{O}_{t}(23)$ is probably about 0.3708 rather than 0.3808 in order that the $\mathrm{W}_{6}-\mathrm{O}$ bond length agrees with the published value, and the $z$ coordinate of the water molecule $\mathrm{Aq}_{2}$ may need to have its sign reversed in order to relieve an improbably short $\mathrm{Aq}_{2} \cdots \mathrm{O}_{t}(9)$ distance of $2.05 \AA$. However, this latter change would result in an even more improbable $\mathrm{Aq}_{2} \cdots \mathrm{Aq}_{2}$ distance of $1.83 \AA$, 
Table 3. $\mathrm{K}_{2.5}\left(\mathrm{H}_{5.5} \mathrm{PtW}_{6} \mathrm{O}_{24}\right) \cdot 2 \mathrm{H}_{2} \mathrm{O}$ : coordinates, $C 2 / m$

\begin{tabular}{|c|c|c|c|c|}
\hline & Site & $x$ & $y$ & $z$ \\
\hline $\mathbf{P t}$ & $4(i)$ & $0.2121(2)$ & 0 & $0.1502(2)$ \\
\hline$W(1,6)$ & $8(j)$ & $0.2328(2)$ & $0.1674(1)$ & $0.1521(2)$ \\
\hline$W(2,4)$ & $8(j)$ & $0.2142(2)$ & 0.0859 (1) & $-0.0562(2)$ \\
\hline$W(3,5)$ & $8(j)$ & $0.2455(2)$ & $0.0808(1)$ & $0.3670(2)$ \\
\hline$K(1)$ & $4(i)$ & $-0.435(3)$ & 0 & $0.363(2)$ \\
\hline $\mathrm{K}(2,4)$ & $8(j)$ & $-0.046(2)$ & $0.212(1)$ & $0.295(2)$ \\
\hline $\mathbf{K}(3)$ & $4(g)$ & $1 / 2$ & $0.232(1)$ & 0 \\
\hline$O(1,4)$ & $8(j)$ & $0.133(3)$ & $0.078(2)$ & $0.203(2)$ \\
\hline $\mathrm{O}(2)$ & $4(i)$ & $0.120(5)$ & 0 & $0.013(5)$ \\
\hline$O(3,6)$ & $8(j)$ & $0.301(3)$ & $0.074(2)$ & $0.101(2)$ \\
\hline $\mathrm{O}(5)$ & $4(I)$ & $0.312(4)$ & 0 & $0.287(3)$ \\
\hline$O(7)$ & $4(i)$ & $0.292(4)$ & 0 & $-0.077(3)$ \\
\hline$O(8,10)$ & $8(j)$ & $0.140(3)$ & $0.149(2)$ & 0.021 \\
\hline$O(9)$ & $4(i)$ & $0.165(5)$ & 0 & 0.393 (4) \\
\hline$O(11,12)$ & $8(j)$ & $0.316(3)$ & $0.135(2)$ & $0.282(3)$ \\
\hline$O(13,15)$ & $8(j)$ & $0.332(4)$ & $0.128(3)$ & $-0.091(3)$ \\
\hline $\mathrm{O}(14,20)$ & $8(j)$ & $0.346(5)$ & $0.216(3)$ & $0.127(4)$ \\
\hline$O(16,18)$ & $8(j)$ & 0.099 (4) & $0.086(2)$ & $-0.166(3)$ \\
\hline$O(17,23)^{*}$ & $8(j)$ & $0.136(5)$ & $0.223(3)$ & $0.193(4)$ \\
\hline$O(19,22)$ & $8(j)$ & $0.142(6)$ & $0.136(3)$ & $0.400(4)$ \\
\hline$O(21,24)$ & $8(j)$ & 0.366 (4) & $0.079(2)$ & 0.469 (3) \\
\hline$A q(1)$ & $4(i)$ & $0.491(6)$ & 0 & $0.144(5)$ \\
\hline $\operatorname{Aq}(2)^{*}$ & $4(h)$ & 0 & $0.046(6)$ & $1 / 2$ \\
\hline
\end{tabular}

suggesting incomplete occupancy of this site or a different interpretation of the misprint.

The $C 2 / m$ coordinates are given in Table 3 , with their e.s.d.'s as estimated from the original (Lee \& Sasaki, 1987; Table 1). Except for the apparent misprints noted above, the average coordinate shifts necessary to produce the higher symmetry are, on average, considerably smaller than the e.s.d.'s. Accordingly, there are no significant changes in the bond lengths nor in the description of the structure.

\section{1,4,10-Trioxa-7,13-diazacyclopentane-7,13-diacetato- copper(II) dihydrate}

The structure of this compound, $\mathrm{C}_{14^{-}}$ $\mathrm{H}_{24} \mathrm{~N}_{2} \mathrm{O}_{7} \mathrm{Cu} .2 \mathrm{H}_{2} \mathrm{O}$, was refined (Urbańczyk-Lipkowska, Gluziński, Krajewski, Koliński, Kemme \& Mishnev, 1989; UGKKKM) in space group $P 4_{3}$ [tetragonal; $a=7.217$ (1), $c=34.553$ (7) $\AA, Z=4$ ]. It should surely be described in $P 4_{3} 2_{1} 2$. The $P 4_{3} 2_{1} 2$ model can be obtained from the coordinates in Table 2 of UGKKKM by incrementing $x$ by $0.5, z$ by 0.25 , and averaging over appropriate pairs of atoms. Since, in some cases, this averaging entailed shifting the coordinates by somewhat more than their e.s.d.'s [but never by more than $0.05 \AA$, except for the disordered oxygen atom $O(10)$ where the necessary shift was $0.09 \AA$, we have obtained the $F_{\text {obs }}$ values and carried out successful refinement in $P 4_{3} 2_{1} 2$.

Included in the list of $1057 F_{\text {obs }}$ values were five of the type $0 k 0$ with $k$ odd, systematic absences in $P 4_{3} 2_{2} 2$; all five were among the smallest entries in the table. The remaining entries were of the type $h k l$ and $\bar{h} k l$, with $|h| \leq k$; when averaged according to Laue symmetry $4 / \mathrm{mmm}$, the value of $R_{\text {merge }}$ was 0.031 for 327 pairs of equivalent reflections. Least-squares refinement in $P 4_{3} 2_{1} 2$ then led to an $R$ of 0.035 for 173 parameters
Table 4. $\mathrm{C}_{14} \mathrm{H}_{24} \mathrm{~N}_{2} \mathrm{O}_{7} \mathrm{Cu} .2 \mathrm{H}_{2} \mathrm{O}$; coordinates, space group $P 4_{3} 2{ }_{1} 2$

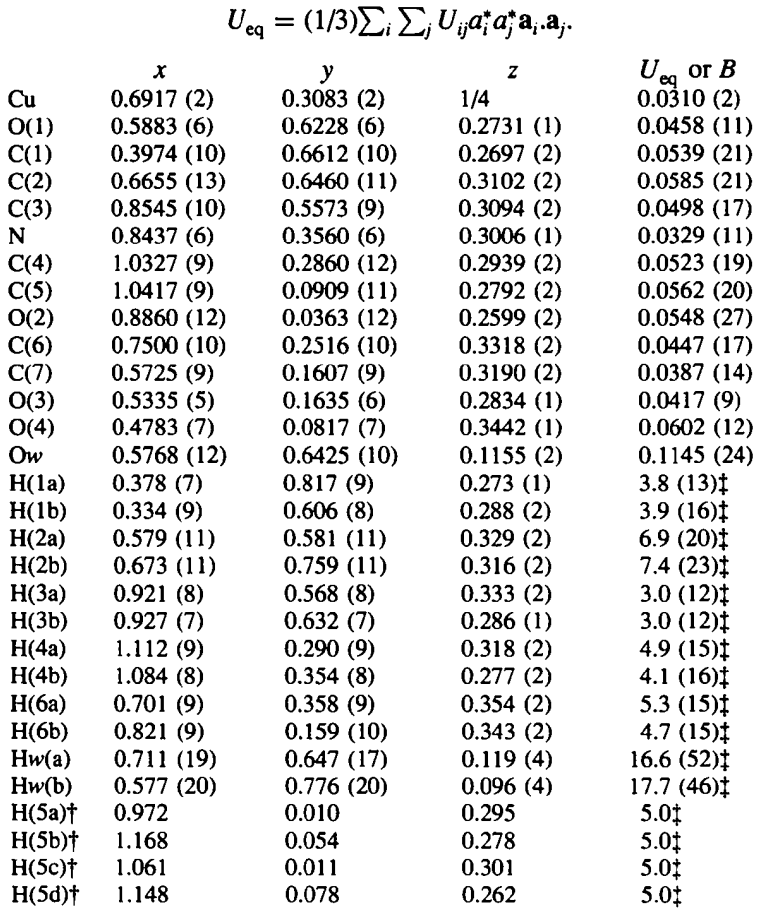

$\dagger$ Site occupancy factor, 0.5 .

$\ddagger$ Isotropic displacement parameter, $B$.

and 725 independent reflections; for their $P 4_{3}$ model, UGKKKM reported an $R$ of 0.039 for (apparently) 342 parameters. However, by averaging the data in point group $4 / \mathrm{mmm}$ we had ignored the effect of anomalous dispersion by $\mathrm{Cu}$ in this enantiomeric structure; accordingly, our final refinements were based on the full (unaveraged) data set, and included a value $\delta f^{\prime \prime}=0.589 e^{-}$for $\mathrm{Cu}$ (International Tables for X-ray Crystallography, 1974; $\mathrm{Cu} K \alpha$ radiation). For this refinement, $R$ converged at 0.041 for 1052 reflections satisfactorily close, we believe, to the 0.039 reported by UGKKKM for their $\mathrm{P4}_{3}$ model with nearly twice as many parameters.

The final $P 4_{3} 2_{1} 2$ parameters are given in Table 4, and a view of the complex is shown in Fig. 1. The resulting bond lengths are changed only trivially from those reported by UGKKKM, and the general description of the structure - including disorder of $\mathrm{O}(10)$ - remains effectively unchanged. The chirality of the molecule is also confirmed, since refinement with $\delta f^{\prime \prime}=-0.589 e^{-}$ led to a significantly higher $R, 0.044$.

\section{$\left[\mathrm{Co}(\mathrm{ox})\left(\mathrm{NH}_{3}\right)(\right.$ dien $\left.)\right] \mathrm{NO}_{3}$}

The structure of one isomer of ammine(diethylenetriamine)oxalatocobalt(III) nitrate was described as monoclinic, space group $C c$, with 
$a=7.717(6), \quad b=12.206(8), \quad c=14.875(8) \AA$, $\beta=121.25(4)^{\circ}, Z=4$ (Couldwell, House \& Penfold, 1975; CHP). It is properly described as orthorhombic, space group Ama2. However, there is more to this situation than a simple recasting of the space group, for the coordinates given by CHP result in impossibly short contacts between the Co complex and the nitrate group, with $\mathrm{C} . \mathrm{O}$ distances down to $1.5 \AA$. Accordingly, a reinvestigation of the structure seemed appropriate.

The vectors (101), $(0 \overline{1} 0),(100)$ define an $A$-centered cell with $a=12.717, \quad b=12.206, c=7.717 \AA$, $\alpha=\beta=\gamma=90.00^{\circ}, Z=4$. The $878 \quad F_{o}$ values obtained from Table II of CHP, after having their indices transformed, were averaged according to Laue symmetry $\mathrm{mm} 2$ (which is equivalent to $\mathrm{mmm}$ in this case, since there are no reflections with $l<0$ ) to yield 503 independent reflections; for the 375 pairs of equivalent reflections, $R_{\text {merge }}$ was 0.019 . After the atom coordinates (Table I, CHP) were transformed and symmetrized, a structure-factor calculation in space group Ama2 led to a disappointing $R$ of 0.25 . However, a subsequent difference map clearly showed that the nitrate group was misplaced, and should be moved by $c a 0.5$ in $y$ (which is equivalent to reversing the signs of the $y$ coordinates for these atoms in the original $C c$ description). After this group (which lies on a twofold axis) was repositioned, refinement proceeded normally to a final $R$ of 0.033 . $\mathrm{H}$ atoms were placed in calculated positions, and not adjusted. Attempts to determine the polarity of the structure were unsuccessful: refinements with the anomalous component $\delta f^{\prime \prime}$ for $\mathrm{Co}$ at either +0.97 or $-0.97 \mathrm{e}^{-}$led to slightly worse agreement than for $\delta f^{\prime \prime}=0$.

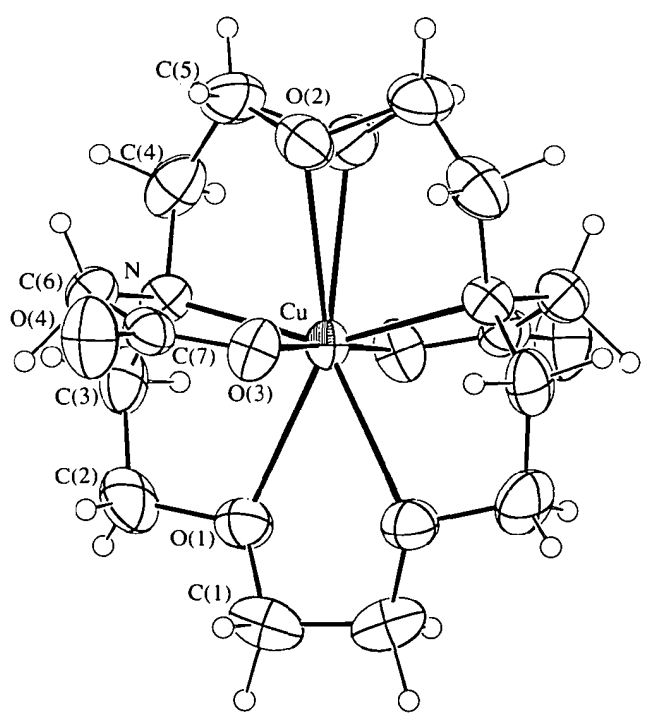

Fig. 1. A view of the $\mathrm{C}_{14} \mathrm{H}_{24} \mathrm{~N}_{2} \mathrm{O}_{7} \mathrm{Cu}$ molecule, with ellipsoids at the $50 \%$ enclosure level. The twofold axis (110 direction) is vertical. Both disordered sites of $\mathrm{O}(2)$ are shown, but only one set of disordered $\mathrm{H}$ atoms on $\mathrm{C}(5)$. $\mathrm{H}$ atoms have been assigned artificially smail isotropic $B$ 's.
Table 5. $\left[\mathrm{Co}(\mathrm{ox})\left(\mathrm{NH}_{3}\right)(\mathrm{dien})\right] \mathrm{NO}_{3}$ : coordinates, space group Ama2

$$
U_{\mathrm{eq}}=(1 / 3) \sum_{i} \sum_{j} U_{i j} a_{i}^{*} a_{j}^{*} \mathbf{a}_{i} \cdot \mathbf{a}_{j} .
$$

$\begin{array}{lcccc} & x & y & z & U_{\text {eq }}\left(\times 10^{4}\right) \\ \text { Co } & 2500 & 2309(9) & 0 & 208(2) \\ \mathrm{O}(1) & 2500 & 3238(7) & -2007(11) & 368(25) \\ \mathrm{O}(2) & 2500 & 1135(8) & -1629(14) & 278(24) \\ \mathrm{O}(3) & 2500 & 3117(6) & -4847(17) & 802(54) \\ \mathrm{O}(4) & 2500 & 874(6) & -4499(8) & 422(39) \\ \mathrm{O}(5) & 5000 & 5000 & 187(25) & 1656(68) \\ \mathrm{O}(6) & 4821(6) & 4186(6) & 2469(16) & 1302(33) \\ \mathrm{N}(1) & 964(3) & 2207(4) & 82(16) & 305(10) \\ \mathrm{N}(2) & 2500 & 3581(8) & 1543(14) & 310(28) \\ \mathrm{N}(3) & 2500 & 1273(9) & 1873(15) & 237(28) \\ \mathrm{N}(5) & 5000 & 5000 & 1741(12) & 399(24) \\ \mathrm{C}(1) & 667(6) & 1503(6) & 1582(11) & 382(17) \\ \mathrm{C}(2) & 1512(5) & 645(5) & 1768(9) & 289(15) \\ \mathrm{C}(5) & 2500 & 2710(10) & -3436(14) & 391(29) \\ \mathrm{C}(6) & 2500 & 1455(8) & -3211(14) & 255(25)\end{array}$

Final coordinates are given in Table 5, and a view of the cation is shown in Fig. 2. Bond lengths and angles are little changed from those reported by CHP except for the nitrate group, which is no longer 'distorted': $\mathrm{N}-\mathrm{O}$ 1.163 (13) (twice), $1.200(21) \AA$; O-N $-\mathrm{O} 118.9(12)$ (twice), $122.2(10)^{\circ}$. A large in-plane libration of the nitrate group, with an apparent r.m.s. amplitude of $c a$ $25^{\circ}$, presumably accounts for the shortening of the $\mathrm{N}-\mathrm{O}$ distances from the usual value of $c a 1.24 \AA$ (Allen, Kennard, Watson, Brammer, Orpen \& Taylor, 1992). The $\mathrm{N}-\mathrm{H} . \mathrm{O}$ hydrogen bonds accepted by the nitrate group are relatively weak, all being over $3.0 \AA$.

\section{Category 2: center of symmetry added}

\section{Bis[diaquo(1,4,7,10-tetraazacyclododecane)nickel(II)] squarate diperchlorate}

The structure of this compound, [Ni(cyclen) $\left.\left(\mathrm{H}_{2} \mathrm{O}\right)_{2}\right]_{2}\left(\mathrm{C}_{4} \mathrm{O}_{4}\right)\left(\mathrm{ClO}_{4}\right)_{2}$, has been described (Bencini, Bianchi, Garcia-España, Jeannin, Julve, Marcelino \& Philoche-Levisalles, 1990; BBGJJMP) in space group $P 2_{1} c n$ [orthorhombic; $a=11.124(3)$, $b=11.461(3), c=25.735(6) \AA ; Z=4]$. It is better described in Pmcn (No. 62; conventional setting, Pnma). Starting coordinates in Pnma were readily obtained from the values in Table III of BBGJJMP [averaging where necessary, and noting that the $x$ coordinate of $\mathrm{Ni}(1)$ is misprinted at 0.2752 rather than, presumably, 0.2572]. Full-matrix least-squares refinement was based on 2992 $F_{\text {obs }}$ values obtained as supplementary material. $* \dagger \mathrm{H}$ atoms were placed in calculated positions $(\mathrm{C}-\mathrm{H} 0.95$, $\mathrm{N}-\mathrm{H} 0.85, \mathrm{O}-\mathrm{H} 0.75 \AA$ ) with the help of difference

* 43 entries in the supplementary table were obviously misprinted, and were omitted; four more reflections were deleted as being obviously aberrant for both the Pnma and the $P 2_{1} c n$ models.

$\dagger$ Lists of structure factors, anisotropic displacement parameters and $\mathrm{H}$-atom coordinates have been deposited with the IUCr (Reference: CR0484). Copies may be obtained through The Managing Editor, International Union of Crystallography, 5 Abbey Square, Chester CH1 2HU, England. 
maps around the water molecules, and not refined. At a late refinement stage it became apparent that one of the perchlorate groups, at $\mathrm{Cl}(B)$, could be better described as disordered between a major and minor site; the minor site is further disordered across the mirror plane, and these $\mathrm{O}$ atoms were assigned fixed isotropic $B$ 's. The remaining atoms were refined with anisotropic $U_{i j}$ 's. At convergence (largest shift, $0.04 \sigma$ ), $R$ was 0.044 for all 2992 reflections. For the $P 2{ }_{1} c n$ model BBGJJMP reported an $R$ of 0.0345 for the 2059 reflections with $I \geq 3 \sigma(I)$; the present $P n m a$ refinement leads to an $R$ of 0.0323 for the 2064 reflections with $F_{\text {obs }} \geq 14.0 \mathrm{e}^{-}$[no values of $\sigma(I)$ were available, so an exact comparison cannot be made]. However, there is a large difference for the very weak reflections - those most sensitive to the centrosymmetric-noncentrosymmetric ambiguity (Schomaker \& Marsh, 1979; Marsh, 1981). A comparison involving the 269 reflections with $F_{\text {obs }}<4.5 \mathrm{e}^{-}$is given in Table 6; this comparison clearly emphasizes not only the better agreement given by the centrosymmetric Pnma model, but also the fact that the small imaginary components to $F_{\text {calc }}$ created by the noncentrosymmetric $P 2_{1} c n$ model results in a systematic disparity between the magnitudes of $F_{\text {calc }}$ and $F_{\text {obs }}$ for the weak reflections (where these imaginary components are important); this disparity nearly vanishes for the centrosymmetric Pnma model, which entails no such imaginary components.

The final Pnma coordinates are given in Table 7, and a view of the two independent dications and the squarate dianion is shown in Fig. 3. In this revised structure, each of the separate entities - the two hydrated $\mathrm{Ni}$ (cyclen) dications, the squarate dianion and the two perchlorate anions - lies across a mirror plane (although one of the perchlorates is disordered). There are small, but highly

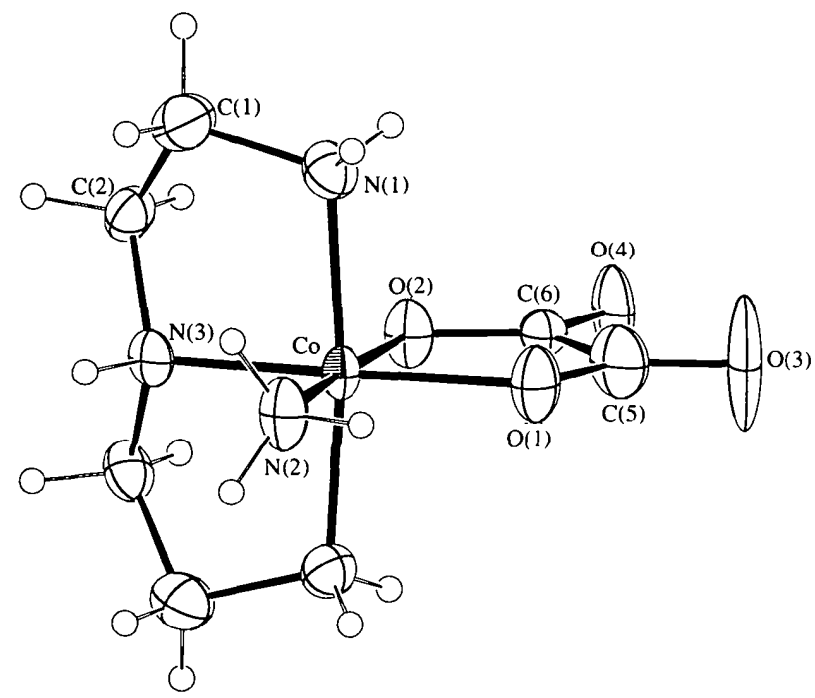

Fig. 2. A view of the $\mathrm{Co}(\mathrm{ox})\left(\mathrm{NH}_{3}\right)$ (dien) ion, with ellipsoids at the $50 \%$ enclosure level. The view is approximately parallel to the crystallographic mirror plane. $\mathrm{H}$ atoms have been assigned artificially small isotropic $B$ 's.
Table 6. [Ni(cyclen $\left.)\left(\mathrm{H}_{2} \mathrm{O}\right)_{2}\right]_{2}\left(\mathrm{C}_{4} \mathrm{O}_{4}\right)\left(\mathrm{ClO}_{4}\right)_{2}$ : some comparisons involving the weakest 269 reflections

$\begin{array}{lcccc}\text { Space group } & \sum_{P 2}\left|F_{\text {obs }}\right| & \sum_{117 \text { calc }} \mid & \sum|\Delta F| & R \\ P \text { cna } & 635.2 & 117.1 & 628.6 & 0.99 \\ P n a & 639.5 & 729.0 & 382.8 & 0.60\end{array}$

Table 7. $\left[\mathrm{Ni}(\right.$ cyclen $\left.)\left(\mathrm{H}_{2} \mathrm{O}\right)_{2}\right]\left(\mathrm{C}_{4} \mathrm{O}_{4}\right)\left(\mathrm{ClO}_{4}\right)_{2}:$ coordinates, space group Pnma $[a=25.735(6)$, $b=11.124(3), c=11.461(3) \AA]$

$$
U_{\text {eq }}=(1 / 3) \sum_{i} \sum_{j} U_{i j} a_{i}^{*} a_{j}^{*} \mathbf{a}_{i} \cdot \mathbf{a}_{j} .
$$

\begin{tabular}{lclrr} 
& $x$ & $y$ & \multicolumn{1}{c}{$z$} & $U_{\text {eq }}\left(\times 10^{4}\right)$ or $B$ \\
$\mathrm{Ni}(A)$ & $3727(2)$ & 2500 & $8585(5)$ & $215(1)$ \\
$\mathrm{Ni}(B)$ & $1778(2)$ & 2500 & $13(5)$ & $208(1)$ \\
$\mathrm{O}(1 A)$ & $3213(1)$ & $1227(2)$ & $7781(2)$ & $385(6)$ \\
$\mathrm{N}(1 A)$ & $4323(2)$ & 2500 & $7313(3)$ & $291(9)$ \\
$\mathrm{N}(2 A)$ & $4138(1)$ & $1044(3)$ & $9227(2)$ & $282(6)$ \\
$\mathrm{N}(3 A)$ & $3389(2)$ & 2500 & $10258(3)$ & $254(8)$ \\
$\mathrm{C}(1 A)$ & $4636(2)$ & $1384(3)$ & $7472(4)$ & $402(9)$ \\
$\mathrm{C}(2 A)$ & $4665(1)$ & $1005(3)$ & $8728(4)$ & $390(9)$ \\
$\mathrm{C}(3 A)$ & $4106(2)$ & $1014(4)$ & $10510(3)$ & $368(8)$ \\
$\mathrm{C}(4 A)$ & $3560(2)$ & $1375(4)$ & $10853(3)$ & $370(8)$ \\
$\mathrm{O}(1 B)$ & $2320(1)$ & $1286(2)$ & $709(2)$ & $290(5)$ \\
$\mathrm{N}(1 B)$ & $2022(2)$ & 2500 & $-1765(4)$ & $267(9)$ \\
$\mathrm{N}(2 B)$ & $1338(1)$ & $1032(3)$ & $-525(2)$ & $285(6)$ \\
$\mathrm{N}(3 B)$ & $1268(2)$ & 2500 & $1437(3)$ & $270(9)$ \\
$\mathrm{C}(1 B)$ & $1820(2)$ & $1364(3)$ & $-2303(3)$ & $346(8)$ \\
$\mathrm{C}(2 B)$ & $1305(2)$ & $1008(3)$ & $-1797(3)$ & $369(9)$ \\
$\mathrm{C}(3 B)$ & $849(1)$ & $1009(3)$ & $123(3)$ & $368(8)$ \\
$\mathrm{C}(4 B)$ & $954(1)$ & $1376(3)$ & $1375(3)$ & $363(8)$ \\
$\mathrm{C}(5)$ & $2469(1)$ & $1840(3)$ & $3734(3)$ & $277(8)$ \\
$\mathrm{C}(6)$ & $2731(1)$ & $1845(3)$ & $4860(3)$ & $262(8)$ \\
$\mathrm{O}(5)$ & $2318(1)$ & $1046(2)$ & $3041(2)$ & $400(7)$ \\
$\mathrm{O}(6)$ & $2892(1)$ & $1057(2)$ & $5553(2)$ & $384(7)$ \\
$\mathrm{Cl}(1)$ & $5970(1)$ & 2500 & $10333(1)$ & $411(3)$ \\
$\mathrm{O}(2)$ & $5848(2)$ & 2500 & $9134(4)$ & $720(17)$ \\
$\mathrm{O}(3)$ & $5496(2)$ & 2500 & $10957(5)$ & $1301(29)$ \\
$\mathrm{O}(4)$ & $6273(2)$ & $1491(3)$ & $10645(4)$ & $972(14)$ \\
$\mathrm{Cl}(1)$ & $4376(1)$ & 2500 & $3903(1)$ & $560(4)$ \\
$\mathrm{O}^{\prime}(2) \dagger$ & $3883(6)$ & 2500 & $4144(20)$ & $2278(10)$ \\
$\mathrm{O}^{\prime}(3) \dagger$ & $4518(7)$ & $1502(12)$ & $3220(12)$ & $1284(35)$ \\
$\mathrm{O}^{\prime}(4) \dagger$ & $4707(6)$ & 2500 & $4845(10)$ & $822(39)$ \\
$\mathrm{O}^{\prime \prime}(2) \ddagger$ & $3943(11)$ & $1827(25)$ & $4776(22)$ & $6.0 \S$ \\
$\mathrm{O}^{\prime \prime}(3) \ddagger$ & $4585(18)$ & $1327(42)$ & $3085(39)$ & $6.0 \S$ \\
$\mathrm{O}^{\prime \prime}(4) \ddagger$ & $4713(13)$ & $3012(37)$ & $4679(32)$ & 6.08 \\
$\mathrm{O}^{\prime \prime}(5) \ddagger$ & $4051(10)$ & $3164(22)$ & $3365(21)$ & $6.0 \S$ \\
& & & &
\end{tabular}

$\dagger$ Site population, $0.64(1)$.

$\ddagger$ Site population, 0.18 .

$\S$ Isotropic displacement parameter, $B$.

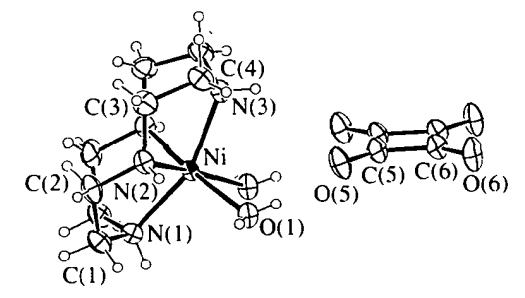

(a)

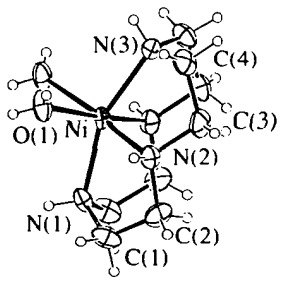

(b)

Fig. 3. A view of the two independent $\mathrm{Ni}($ cyclen $)\left(\mathrm{H}_{2} \mathrm{O}\right)_{2}$ dications and the squarate dianion in the structure of [Ni(cyclen) $\left.\left(\mathrm{H}_{2} \mathrm{O}\right)_{2}\right]_{2}\left(\mathrm{C}_{4} \mathrm{O}_{4}\right)\left(\mathrm{ClO}_{4}\right)_{2}$. The view is approximately perpendicular to the crystallographic mirror plane. Ellipsoids are at the $50 \%$ enclosure level; $\mathrm{H}$ atoms have been assigned artificially small isotropic $B$ 's. 
significant, differences in the bond lengths about the two $\mathrm{Ni}$ atoms - most noticeably the $\mathrm{Ni}-\mathrm{H}_{2} \mathrm{O}$ distances, at 2.146 (3) $\AA$ in $A$ and 2.098 (2) $\AA$ in $B$; the bond angles are more nearly uniform. All the interatomic distances are more precise - and surely more accurate - than those resulting from the $P 2{ }_{1} c n$ refinement. For example, in the earlier description the $\mathrm{N}-\mathrm{C}$ distances in the cyclen groups covered the improbable range 1.35(1)-1.63(2) $\AA$; in the revised structure the range is from $1.461(5)$ to $1.498(5) \AA$. There is a distinct pattern to these $\mathrm{N}-\mathrm{C}$ distances: those involving $\mathrm{N}(1)$ and $\mathrm{N}(3)$, which are trans to one another in this tetradentate ligand, are statistically equal at 1.493 (3) $\AA$, while those to $\mathrm{N}(2)$, in cis positions, are equal at $1.467(3) \AA$. The $N(2)$ atoms also form slightly shorter $\mathrm{Ni}-\mathrm{N}$ bonds, and are more nearly planar in their bonding (excluding the proton). The water molecules form strong hydrogen bonds to $\mathrm{O}$ atoms of the squarate dianion; the $\mathrm{N}$ atoms form, at best, weak hydrogen bonds to the perchlorate ions.

\section{$\mathrm{Ba}_{2}\left[\mathrm{Pt}_{2}\left(\mathrm{P}_{2} \mathrm{O}_{5} \mathrm{H}_{2}\right)_{4}\right] .8 \mathrm{H}_{2} \mathrm{O}$}

This structure was described (Bär, Englmeier, Gliemann, Klement \& Range, 1990) in space group Pc [monoclinic; $\quad a=9.5452(8), \quad b=19.459(2)$, $\left.c=7.6611(8) \AA, \beta=90.758(8)^{\circ}, Z=2\right]$. No heavy (Ba, Pt or P) atom need be shifted by more than $0.07 \AA$, nor any $\mathrm{O}$ atoms by more than $0.17 \AA$, to conform to $P 2_{1} / c$; since these shifts are typical of the distortions that arise when a centrosymmetric structure is refined in a noncentrosymmetric space group, we have little doubt that the structure should be described in $P 2_{1} / c$. Tentative $P 2_{1} / c$ coordinates (Table 8 ) are obtained by shifting the origin to $(0.214,0.25,-0.094)$ and averaging over appropriate pairs of atoms. This revised model results in considerably more satisfactory bond lengths; for example, the range of $\mathrm{Pt}-\mathrm{P}$ distances is now $2.309-2.330 \AA$, compared with $2.270-2.391 \AA$ for the earlier PC model. Moreover, the $\mathrm{P}-\mathrm{O}$ (terminal) bond lengths in the $\mathrm{P}_{2} \mathrm{O}_{5} \mathrm{H}_{2}$ ('POP') groups now fall into two distinct groups, at $1.511(11)$ and $1.578(10) \AA$ (values in parentheses are scatter e.s.d.'s), indicating that the $\mathrm{H}$ atoms are ordered as they form $\mathrm{O}-\mathrm{H} \cdots \mathrm{O}$ bonds between POP groups; in the earlier description, these $\mathrm{P}-\mathrm{O}$ bond lengths ranged from 1.41 to $1.61 \AA$ and no systematic distinction could be made. The bridging $\mathrm{P}-\mathrm{O}$ bond lengths are at $1.632(18) \AA$.

Unfortunately, no supplementary material is available for this paper (nor for the following two examples), so we are unable to carry out further refinement in $P 2_{1} / c$.

\section{$\mathrm{Ba}_{3} \mathrm{Sn}_{2} \mathrm{P}_{4}$}

The structure of this compound, originally described and refined (Eisenmann, Jordan \& Schäfer, 1986) in space group $P 2_{1}$ [monoclinic; $a=7.886(4)$, $b=19.278(8), c=7.869$ (4) $\left.\AA, \beta=112.8(1)^{\circ}, Z=4\right]$, should undoubtedly be described in $P 2_{1} / c$. The $P 2_{1} / c$
Table 8. $\mathrm{Ba}_{2}\left[\mathrm{Pt}_{2}\left(\mathrm{P}_{2} \mathrm{O}_{5} \mathrm{H}_{2}\right)_{4}\right] .8 \mathrm{H}_{2} \mathrm{O}$ : tentative coordinates $\left(\times 10^{4}\right)$, space group $P 2_{1} / c$

\begin{tabular}{lr} 
& \multicolumn{1}{c}{$x$} \\
$\mathrm{Pt}$ & -252 \\
$\mathrm{Ba}$ & 4994 \\
$\mathrm{P}(1)$ & -1635 \\
$\mathrm{P}(2)$ & 1622 \\
$\mathrm{P}(3)$ & 1174 \\
$\mathrm{P}(4)$ & -2147 \\
$\mathrm{O}(1)$ & -1289 \\
$\mathrm{O}(2)$ & 2392 \\
$\mathrm{O}(11)$ & -3214 \\
$\mathrm{O}(12)$ & -1258 \\
$\mathrm{O}(21)$ & 1350 \\
$\mathrm{O}(22)$ & 2842 \\
$\mathrm{O}(31)$ & 2650 \\
$\mathrm{O}(32)$ & 506 \\
$\mathrm{O}(41)$ & -2140 \\
$\mathrm{O}(42)$ & -3629 \\
$\mathrm{O}(91)$ & 5072 \\
$\mathrm{O}(92)$ & 3013 \\
$\mathrm{O}(93)$ & 6871 \\
$\mathrm{O}(94)$ & 4958 \\
&
\end{tabular}

$\begin{array}{rr}y & z \\ 166 & 1847 \\ 1911 & 2588 \\ -802 & 2092 \\ -498 & 2772 \\ 1132 & 1599 \\ 834 & 996 \\ -1334 & 485 \\ -824 & 1090 \\ -718 & 2100 \\ -1275 & 3702 \\ -1110 & 3930 \\ -86 & 3670 \\ 1103 & 2275 \\ 1820 & 2300 \\ 1594 & 1465 \\ 566 & 1635 \\ 1700 & -1125 \\ 2344 & 5205 \\ 2192 & 5350 \\ 915 & 5070\end{array}$

Table 9. $\mathrm{Ba}_{3} \mathrm{Sn}_{2} \mathrm{P}_{4}$ : tentative coordinates, space group $P 2_{1} / c$

$\begin{array}{lccr} & x & y & z \\ \mathrm{Ba}(1) & 0.2982 & 0.1884 & 0.4328 \\ \mathrm{Ba}(3) & 0.7694 & 0.0614 & 0.4559 \\ \mathrm{Ba}(5) & 0.8178 & 0.1947 & -0.0519 \\ \mathrm{Sn}(1) & 0.3526 & 0.1202 & -0.0876 \\ \mathrm{Sn}(2) & 0.2252 & 0.0058 & 0.0513 \\ \mathrm{P}(1) & 0.0272 & 0.0571 & 0.2128 \\ \mathrm{P}(3) & 0.5349 & 0.0714 & 0.7232 \\ \mathrm{P}(5) & 0.0657 & 0.1788 & 0.6954 \\ \mathrm{P}(6) & 0.5602 & 0.1894 & 0.1875\end{array}$

coordinates (Table 9) are obtained by decrementing the $y$ coordinates (Eisenmann, Jordan \& Schäfer, 1986) by 0.1919 and the $z$ coordinates by 0.25 (in order to place the origin at a center of symmetry) and averaging over related pairs of atoms; during this averaging, no coordinate need be shifted by as much as $0.1 \AA$. The revised coordinates lead to appreciably more regular bond distances and angles. Lacking a table of $F_{\text {obs }}$ values, we are unable to carry out refinements in $P 2_{1} / c$ or to check on the additional systematic absences $(h 0 l, l$ odd).

\section{(2,2'-Bipyridine)(iminodiacetato)copper(II) hexahydrate}

The structure of this compound, $\mathrm{C}_{14}$ $\mathrm{H}_{13} \mathrm{CuN}_{3} \mathrm{O}_{10} \cdot 6 \mathrm{H}_{2} \mathrm{O}$, was described and refined (Castiñeiras, Abarca, De La Cueva, Gonzalez \& Niclos, 1993; CACGN) in space group $P 1$ [triclinic; $a=10.593(1), \quad b=12.454(1), \quad c=7.923(1) \AA$, $\alpha=102.64(1), \beta=107.40(1), \gamma=83.68(1)^{\circ}, Z=2$ ] Pairs of molecules form effectively centrosymmetric dimers, and there seems no reason not to describe the structure in space group $P \overline{1}$. Ater the origin is placed at the center of the dimer and coordinates of pairs of equivalent atoms are averaged, the $P \overline{1}$ coordinates in Table 10 result. [The original $P 1$ coordinates in Table 2 of CACGN contain three obvious misprints: the $y$ 
Table 10. (2,2'-Bipyridine)(iminodiacetato)copper(II) hexahydrate: tentative coordinates, space group $P \overline{1}$

$\begin{array}{lrcc} & x & y & z \\ \mathrm{Cu} & 0.14074 & 0.11608 & -0.12630 \\ \mathrm{O}(1) & 0.2018 & 0.1912 & 0.3950 \\ \mathrm{O}(2) & 0.6445 & -0.3568 & 0.3722 \\ \mathrm{O}(5) & -0.0222 & 0.4012 & 0.2870 \\ \mathrm{O}(7) & -0.2592 & -0.4982 & 0.1024 \\ \mathrm{O}(9) & -0.3724 & 0.3710 & -0.2288 \\ \mathrm{O}(11) & -0.0096 & 0.0230 & -0.2001 \\ \mathrm{O}(12) & -0.2098 & 0.0132 & -0.1698 \\ \mathrm{O}(14) & 0.0628 & 0.2103 & -0.3490 \\ \mathrm{O}(15) & -0.0425 & 0.3711 & -0.3912 \\ \mathrm{O}(110) & 0.2936 & -0.4706 & 0.4509 \\ \mathrm{~N}(11) & 0.0240 & 0.2310 & -0.0145 \\ \mathrm{~N}(12) & 0.2500 & 0.0078 & -0.2540 \\ \mathrm{~N}(13) & 0.3156 & 0.1862 & -0.0118 \\ \mathrm{C}(11) & -0.1084 & 0.0628 & -0.1440 \\ \mathrm{C}(12) & -0.1002 & 0.1790 & -0.0332 \\ \mathrm{C}(13) & 0.0015 & 0.3282 & -0.1024 \\ \mathrm{C}(14) & 0.0079 & 0.2992 & -0.2967 \\ \mathrm{C}(15) & 0.2056 & -0.0826 & -0.3770 \\ \mathrm{C}(16) & 0.2870 & -0.1494 & -0.4682 \\ \mathrm{C}(17) & 0.4158 & -0.1219 & -0.4340 \\ \mathrm{C}(18) & 0.4630 & -0.0290 & -0.3074 \\ \mathrm{C}(19) & 0.3761 & 0.0351 & -0.2200 \\ \mathrm{C}(110) & 0.4132 & 0.1370 & -0.0814 \\ \mathrm{C}(111) & 0.5388 & 0.1775 & -0.0278 \\ \mathrm{C}(112) & 0.5645 & 0.2726 & 0.1036 \\ \mathrm{C}(113) & 0.4654 & 0.3227 & 0.1776 \\ \mathrm{C}(114) & 0.3426 & 0.2772 & 0.1176 \\ & & & \end{array}$

coordinate of $\mathrm{C}(11)$ should be -0.0536 rather than -0.0336 , the $z$ coordinate of $C(19)$ should be negative rather than positive, and the $x$ coordinate of $C(210)$ should be -0.5573 rather than -0.3573 in order to reproduce the reported bond lengths.]

This revised structure yields bond lengths and angles that are considerably more reasonable than those reported by CACGN. For instance, $\mathrm{C}-\mathrm{C}$ distances in the pyridyl rings, which ranged from 1.280 (5) to $1.495(5) \AA$ in the earlier description, are now effectively equal, ranging from 1.376 to $1.393 \AA$. Bonding about the $\mathrm{Cu}$ atom is more regular, and, of course, the two $\mathrm{Cu}$ atoms in the unit cell are now equivalent, by symmetry.

\section{Category 3: change in both Laue group and centrosymmetry}

$\mathrm{Cs}_{6} \mathrm{~W}_{11} \mathrm{O}_{36}$

The structure of this compound was described and refined (Okada, Marumo \& Iwai, 1978; OMI) in space group $A a$ [monoclinic; $a=37.800(5), b=7.261$ (1), $c=12.577$ (2) $\left.\AA, \beta=102.81(1)^{\circ}, Z=4\right]$. It is correctly described as rhombohedral, space group $R \overline{3} c$. The vectors $\left(1-\frac{1}{2} \frac{1}{2}\right),\left(1 \frac{1}{2} \frac{1}{2}\right)$ and (101) define a rhombohedral cell with $a=37.097 \AA, \alpha=11.24^{\circ}, Z=2$; the corresponding hexagonal cell (which we use hereinafter), based on ( $\left(0 \frac{1}{2} \frac{1}{2}\right),(010)$ and (302), has $a=7.261$, $c=110.58 \AA, Z=6$. The $2315 F_{\text {obs }}^{2}$ values recovered from SUP 32957, when averaged according to Laue symmetry $\overline{3} m$, led to 1004 independent values; for the 258 pairs of equivalent reflections, $R_{\text {merge }}$ was 0.047 . Coordinates from Table 2 of OMI, when suitably
Table 11. $\mathrm{Cs}_{6} \mathrm{~W}_{11} \mathrm{O}_{36}$ : coordinates, space group $R \overline{3} c$ $U_{\mathrm{eq}}=(1 / 3) \sum_{i} \sum_{j j} U_{i j} a_{i}^{*} a_{j}^{*} \mathbf{a}_{i} \cdot \mathbf{a}_{j}$.

\begin{tabular}{lllll} 
& \multicolumn{1}{c}{$x$} & \multicolumn{1}{c}{$y$} & \multicolumn{1}{c}{$z$} & $U_{\text {eq }}$ or $B$ \\
$\mathrm{~W}(1)$ & $0.5306(2)$ & 0 & $3 / 4$ & $0.0109(3)$ \\
$\mathrm{W}(2)$ & 0 & 0 & $0.44461(2)$ & $0.0109(3)$ \\
$\mathrm{W}(3)$ & $0.4865(2)$ & $0.4805(2)$ & $0.13838(1)$ & $0.0127(2)$ \\
$\mathrm{Cs}(1)$ & 0 & 0 & $0.34300(3)$ & $0.0302(6)$ \\
$\mathrm{Cs}(2)$ & 0 & 0 & $0.38338(3)$ & $0.0319(5)$ \\
$\mathrm{Cs}(3)$ & 0 & 0 & $0.77106(3)$ & $0.0269(5)$ \\
$\mathrm{O}(1)$ & $0.201(4)$ & $0.422(3)$ & $0.09918(14)$ & $1.2(3) \dagger$ \\
$\mathrm{O}(2)$ & $0.110(4)$ & $0.247(3)$ & $0.02735(15)$ & $1.6(3) \dagger$ \\
$\mathrm{O}(3)$ & $0.463(4)$ & $0.914(3)$ & $0.11939(14)$ & $1.3(3) \dagger$ \\
$\mathrm{O}(4)$ & $0.543(4)$ & $0.062(3)$ & $0.15346(15)$ & $1.7(3) \dagger$ \\
$\mathrm{O}(5)$ & $0.465(4)$ & $0.913(2)$ & $0.07949(12)$ & $0.7(2) \dagger$ \\
$\mathrm{O}(6)$ & $0.422(3)$ & $0.197(4)$ & $0.13361(13)$ & $0.9(3) \dagger$
\end{tabular}

$\dagger$ Isotropic displacement parameter, $B$.

Table 12. $\mathrm{Cs}_{6} \mathrm{~W}_{11} \mathrm{O}_{36}: \mathrm{W}-\mathrm{O}$ and $\mathrm{Cs}-\mathrm{O}$ distances

$\begin{array}{llll}\mathrm{W}(1)-\mathrm{O}(5) & 1.72(2)(2 X) & \mathrm{Cs}(1)-\mathrm{O}(4) & 3.05(2)(3 X) \\ \mathrm{W}(1)-\mathrm{O}(1) & 1.86(2)(2 X) & \mathrm{Cs}(1)-\mathrm{O}(2) & 3.28(2)(3 X) \\ \mathrm{W}(1)-\mathrm{O}(5) & 2.15(2)(2 X) & \mathrm{Cs}(2)-\mathrm{O}(6) & 3.26(2)(3 X) \\ \mathrm{W}(2)-\mathrm{O}(3) & 1.79(2)(3 X) & \mathrm{Cs}(2)-\mathrm{O}(1) & 3.28(2)(3 X) \\ \mathrm{W}(2)-\mathrm{O}(1) & 2.04(2)(3 X) & & \\ & & \mathrm{Cs}(3)-\mathrm{O}(3) & 3.12(2)(3 X) \\ \mathrm{W}(3)-\mathrm{O}(4) & 1.70(2) & \mathrm{Cs}(3)-\mathrm{O}(5) & 3.26(2)(3 X) \\ \mathrm{W}(3)-\mathrm{O}(2) & 1.91(2) & & \\ \mathrm{W}(3)-\mathrm{O}(6) & 1.92(2) & & \\ \mathrm{W}(3)-\mathrm{O}(2) & 1.93(2) & & \\ \mathrm{W}(3)-\mathrm{O}(6) & 1.94(2) & & \\ \mathrm{W}(3)-\mathrm{O}(3) & 2.18(2) & & \end{array}$

transformed, agree well with the symmetry of $R \overline{3} c$ and, when averaged, were our starting values. Refinement proceeded routinely to $R=0.056$ for 70 parameters, compared with 0.057 for, apparently, 297 parameters in the $A a$ refinement by OMI. Our final $R \overline{3} c$ coordinates are given in Table 11.

The $\mathrm{W}-\mathrm{O}$ and $\mathrm{Cs}-\mathrm{O}$ distances out to $3.4 \AA$ are given in Table 12; they differ from those obtained by OMI by as much as $0.2 \AA$. All three $\mathrm{W}$ atoms show distorted octahedral coordination; $W(1)$ lies on a twofold axis, W(2) on a threefold axis, and W(3) in a general position. The short $\mathrm{W}(1)-\mathrm{O}(5)$ and $\mathrm{W}(3)-\mathrm{O}(4)$ distances suggest double bonds (Allen, Kennard, Watson, Brammer, Orpen \& Taylor, 1992). All Cs atoms lie on threefold axes; the coordination about $\mathrm{Cs}(2)$ and $\operatorname{Cs}(3)$ is distorted octahedral while that about $\operatorname{Cs}(1)$ is approximately trigonal prismatic. Five of the $\mathrm{O}$ atoms show threefold coordination; the sixth, $\mathrm{O}(4)$, has but two close neighbors.

The earlier authors (OMI) noted that they were unable to derive a reasonable centrosymmetric model (which would have conformed to space group $A 2 / a$ ). It seems probable that their choice of origin was incorrect. Because of the stoichiometry of the compound, one $\mathrm{W}$ atom must occupy a special position in $A 2 / a$; OMI apparently attempted to place $\mathrm{W}(1)$ on a center of symmetry, whereas in the revised structure $\mathrm{W}(1)$ lies on a twofold axis of symmetry but none lies on a center. The additional oversight - failure to find the rhombohedral 
cell - may have been due, in part, to its extreme obliquity $\left(\alpha=11.24^{\circ}\right)$ or to the length $(110.58 \AA)$ of the $c$ axis in the hexagonal setting.

\section{Concluding remarks}

It is clear that we, the crystallographic community, must be on continuous guard against misrepresenting the space group in a crystallographic analysis. Many safeguards have already been implemented: cell-reduction programs supplied with most diffractometer systems are far more reliable than they were in the past, and computer programs such as MISSYM (Le Page, 1988) can perform routine checks for additional symmetry. Why then do space-group errors continue to occur?

In the case of Category 1 errors - failure to find the correct Laue symmetry - we find in this compilation two types of situations that may lead to failure of a cellreduction program: (1) apparent deviations from a higher correct lattice symmetry may be greater than whatever tolerances the reduction program considers; in the case of the cluster compound (Demartin, Iapalucci \& Longoni, 1993), the measured cell angles for the monoclinic description differ from $90^{\circ}$ by nearly $0.3^{\circ}$, in the face of precision estimates of about $0.04^{\circ}$; (2) the correct cell may have dimensions so unusual as, perhaps, to be rejected by the reduction program, as in the case of $\mathrm{Cs}_{6} \mathrm{~W}_{11} \mathrm{O}_{36}$ (Okada, Marumo \& Iwai, 1978). In such cases, deduction of the correct symmetry may depend on an analysis of the final structure (as we have done here) or, preferably, on a check of the Laue symmetry as manifested by the intensity measurements. Indeed, it is particularly important that the correct Laue symmetry be recognized at the time of data collection, so that an appropriate region of reciprocal space is surveyed. A sensible procedure would be to follow the recommendation of Ibers (1967), among others, to collect intensity data for the entire sphere of reflection; these intensities could then be matched according to the various possible Laue groups. Such a procedure would surely have led Urbańczyk-Lipkowska, Gluziński, Krajewski, Koliński, Kemme \& Mishner (1989) to the correct tetragonal Laue group and space group.

Deciding the Category 2 issue - whether or not the space group is centrosymmetric - may be complicated by the fact that refinement of a centrosymmetric structure in a noncentrosymmetric space group leads to nearsingularities and, hence, to large distortions (typically up to $0.2 \AA$ or so) which may appear to be real. Furthermore, initial statistical tests for centrosymmetry may well be biased towards a noncentrosymmetric indication if the structure contains a small number of heavy atoms (Hargreaves, 1955) or if the weak reflections have been deleted from the data set (Marsh, 1981). A reasonable procedure is to search for a centrosymmetric description if it is at all possible, resorting to a noncentrosymmetric description only if the search is unsuccessful. However, in at least one of the examples (Okada, Manumo \& Iwai, 1978) such a procedure was apparently tried, and failed.

Finally, a referee suggests that it would be well to emphasize why it matters that the symmetry be correct, noting that noncrystallographers 'are prone to thinking papers like this one are hopelessly pedantic'. It is tempting to knock that complaint aside with the comment that almost all details, such as the precise conditions for a chemical reaction, may be considered 'hopelessly pedantic' by scientists in other fields. But that is beside the point: accepting incorrect results in order to avoid the label 'pendantic' is contrary to accepted standards of scientific behavior. If a more practical answer is still needed, one need only point to the many areas of science - including the interpretation of solid-state spectroscopic data and the increasingly important field of nonlinear optics - where knowledge of the correct crystal symmetry is of vital importance. We can think of no valid excuse for considering the choice of space group as unimportant, or for condoning an incorrect choice.

\section{References}

allen, F. H., Kennard, O., Watson, D. G., Brammer, L., Orpen, A. G. \& TAYLOR, R. (1992). International Tables for Crystallography, Vol. C, p. 704. Dordrecht: Kluwer Academic Publishers.

Bär, L., ENGLMeIER, H., GliemanN, G., KLement, U. \& RANGE, K.-J. (1990). Inorg. Chem. 29, 1162-1168.

Bencin, A., Bianch, A., Garcia-España, E., Jeannin, Y., Julve, M., Marcelino, V. \& Philoche-Levisalles, M. (1990). Inorg. Chem. 29, 963-970.

Castiñeiras, A., Abarca, M. E., De la Cueva, I., Gonzalez, J. M. \& NicLos, J. (1993). J. Coord. Chem. 30, 273-281.

Couldwell, M. C., House, D. A. \& Penfold, B. R. (1975). Inorg. Chim. Acta, 13, 61-66.

Demartin, F., lapalucci, M. C. \& Longoni, G. (1993). Inorg. Chem. 32, 5536-5543.

EISENMANN, B., JoRdan, H. \& SchäFER, H. (1986). Z; Anorg. Allg. Chem. 532, 73-80.

HaRgreaves, A. (1955). Acta Cryst. 8, 12-14.

IBERS, J. A. (1967). Acta Cryst. 22, 604-605.

LEE, U. \& SASAKI, Y. (1987). J. Korean Chem. Soc. 31, 118-120.

Le PAGe, Y. (1988). J. Appl. Cryst. 21, 983-984.

MARSH, R. E. (1981). Acta Cryst. B37, 1985-1988.

Marsh, R. E. \& HerbsteIn, F. (1988). Acta Cryst. B44, 77-88.

OKadA, K., MaRumo, F. \& IWAi, S. (1978). Acta Cryst. B34, 50-54.

Plötz, K.-B. \& Müller-Buschbaum, HK. (1982). Z. Anorg. Allg. Chem. 488, 38-44.

Schomaker, V. \& MARSh, R. E. (1979). Acta Cryst. B35, 1933-1934. URBAŃCZYK-LIPKOWSKA, Z., GLUZIŃSKI, P., KRAJEWSKI, J. W., KolísSi, R. A., KeMme, A. \& Mishnev, A. (1989). J. Crystallogr. Spectrosc. Res. 19, 387-397. 